\title{
Relationship between gestational age and endoglin levels in maternal and cord blood
}

\author{
Simmi Kharb ${ }^{1}$, R. Tiwari ${ }^{1}$, S. Nanda ${ }^{2}$ \\ ${ }^{1}$ Department of Biochemistry, Pt. B.D. Sharma University of Health Sciences, Rohtak, India \\ ${ }^{2}$ Department of Biochemistry, Obstetrics and Gynecology, Pt. B.D. Sharma PGIMS, Rohtak, India
}

Received: 10 January 2016

Revised: 12 January 2016

Accepted: 08 February 2016

\author{
*Correspondence: \\ Dr. Simmi Kharb, \\ E-mail: simmikh@gmail.com
}

Copyright: (c) the author(s), publisher and licensee Medip Academy. This is an open-access article distributed under the terms of the Creative Commons Attribution Non-Commercial License, which permits unrestricted non-commercial use, distribution, and reproduction in any medium, provided the original work is properly cited.

\begin{abstract}
Background: Poor placentation at early gestational age is an important predisposing condition for the development of preeclampsia. The present study was designed to study the relationship of gestational age with endoglin levels in maternal and cord blood of normal and pre-eclamptic women.

Methods: The present study was conducted in fifty pregnant women that were grouped as: group 1 (control, $n=25)$ comprising of normotensive women immediately after delivery, group 2 (study group, $\mathrm{n}=25$ ) comprising of age -and sex- matched pre-eclamptic women. Study samples were drawn (maternal venous blood and umbilical cord blood). Endoglin was analyzed by competitive enzyme linked immunosorbent assay.

Results: Maternal serum endoglin levels were decreased in group II as compared to group I. Maternal endoglin showed a positive correlation with gestational age in both normotensive and preeclamptic women. Cord blood endoglin showed negative correlation with gestational age in both normotensive women and preeclamptics. A significant positive correlation was found between maternal and cord blood endoglin levels with birth weight in preeclamptic mothers. Pre-eclamptics with birth weight less than $2.5 \mathrm{~kg}$ had lower maternal blood endoglin levels as compared to controls.
\end{abstract}

Conclusions: These finding suggest that endoglin levels may responsible for the pathogenesis of PE and/or IUGR.

Keywords: Endoglin, Gestational age, Pregnancy, Preeclamptics, Cord blood

\section{INTRODUCTION}

Placenta is responsible for organizing foetal growth and maternal condition during gestation and placental dysfunction occurs during pathological conditions of pregnancy such as preeclampsia and intrauterine growth restriction (IUGR). Preeclampsia frequently results in IUGR and premature delivery. ${ }^{1}$ In response to hypoxic microenvironment, antiangiogenic cytokines are released from the placenta. In pre-eclamptic patients, increased levels of various antiangiogenic molecules are detectable namely, soluble form of vascular endothelial growth factor (VEGF) receptor 1 (sVEGFR1or sFlt1) and soluble form of endoglin (sEng). sFlt1 suppresses VEGFmediated and placental growth factor- (PlGF-) mediated signaling. And sEng disturbs transforming growth factor $\beta$-(TGF $\beta$-) mediated signaling. ${ }^{2,3}$

The onset of preeclampsia is not the only pathological event, and it is rather triggered by various predisposing factors that induce circulatory disorders. ${ }^{4}$ Poor placentation at early gestational age is an important predisposing condition for the development of preeclampsia. Blood canals in placenta get narrowed because of insufficient arterial remodelling making it hypoxic and release a series of pro-inflammatory factors 
that damage maternal circulatory system. This is responsible for the two stages of preeclampsia namely, poor placentation in early gestational period (stage I) and maternal systemic dysfunction in later period (stage II). As maternal vascular resistance increases, blood pressure induces further dysfunctions and placenta-derived factors further induce maternal systemic dysfunction.

Studies are available regarding maternal systemic dysfunctions; however, limited information is available regarding pathological events in foeto-placental side, especially during later half of gestation and at the time of birth. Hence the present study was designed to study the relationship of gestational age with endoglin levels in maternal and cord blood of normal and preeclamptic women.

\section{METHODS}

The present study was conducted in the Department of Biochemistry in collaboration with Department of Obstetrics and Gynaecology, Pt. B.D. Sharma, PGIMS, Rohtak. Endoglin levels were analyzed in maternal and cord blood in women with preeclampsia and compared with those of normotensive pregnant women. An informed consent was taken from all the patients and the research protocol was approved by the Institutional Review Board. Women with history of smoking, chronic hypertension, any metabolic disorder before or during pregnancy or presence of high risk factors like anemia, heart disease, diabetes, renal disease were excluded.

Fifty pregnant women were selected and grouped as: group 1 (control) comprising of twenty five normotensive women immediately after delivery. Group 2 (study group) comprising of age-and sex-matched twenty five pre-eclamptic women. Study samples were drawn (maternal venous blood and umbilical cord blood). Endoglin was analyzed by competitive enzyme linked immunosorbent assay. ${ }^{5}$ SPSS version 20; Student's t-test and regression analysis were applied.

\section{RESULTS}

In the present study, maternal serum endoglin levels were decreased in group II as compared to group I (5.25 \pm 0.52 vs $6.64 \pm 0.30 \mathrm{ng} / \mathrm{ml}, \mathrm{p}<0.001$; Table 1$)$. Cord blood endoglin levels were $99.39 \%$ of maternal levels of endoglin in groups I and $95.42 \%$ of maternal levels of endoglin in group II.

Maternal endoglin were higher in mothers with male babies as compared to those with female babies in group I ( $p>0.05$ ). Cord blood endoglin was higher in male babies of normotensive mothers as compared to female counterparts $(p>0.05)$. Maternal endoglin levels were higher in case of female babies as compared to male counterparts in group II ( $\mathrm{p}>0.05)$. In male babies, cord blood endoglin levels were higher as compared to female babies cord blood in group II ( $\mathrm{p}>0.05)$.

Maternal endoglin showed a positive correlation with gestational age in both normotensive and pre-eclamptic women but, it was not statistically significant $(\mathrm{r}=0.120$, $\mathrm{p}>0.05 ; \mathrm{r}=0.099, \mathrm{p}>0.05)$. Cord blood endoglin showed negative correlation with gestational age in both normotensive women and pre-eclamptic but, it was not statistically significant $(\mathrm{r}=-0.167, \mathrm{p}>0.05 ; \mathrm{r}=-0.318$, $\mathrm{p}>0.05)$.

A significant positive correlation was found between maternal endoglin levels and birth weight in normotensive women $(\mathrm{r}=0.403, \mathrm{p}<0.05)$. A positive correlation was observed between cord blood endoglin levels and birth weight normotensive pregnant women $(\mathrm{r}=0.404, \mathrm{p}<0.05)$, it was statistically significant. A significant positive correlation was found between maternal endoglin levels and birth weight in preeclamptic mothers $(\mathrm{r}=0.087, \mathrm{p}>0.05)$ A positive correlation was observed between cord blood endoglin levels and birth weight in pre-eclamptic mothers, but, it was not statistically significant $(r=0.097, \mathrm{p}>0.05)$. Preeclamptics with birth weight less than $2.5 \mathrm{~kg}$ had lower endoglin levels as compared to controls (5.25+ $0.52 \mathrm{ng} / \mathrm{ml}$ vs. $6.64+0.30 \mathrm{ng} / \mathrm{ml}, \mathrm{p}<0.05)$ in maternal blood.

Table 1: Maternal and cord blood endoglin levels in both groups [mean $\pm \mathrm{SD}, \mathrm{ng} / \mathrm{dl}]$.

\begin{tabular}{|lllll|}
\hline & Group I & & Group II & Cord \\
\hline & Maternal & Cord & Maternal & . \\
\hline Endoglin $(\mathrm{ng} / \mathrm{ml})$ total & $6.64 \pm 0.30$ & $6.60 \pm 0.28$ & $5.25 \pm 0.52$ & $5.01 \pm 0.58$ \\
\hline Endoglin $(\mathrm{ng} / \mathrm{ml})$ male babies & $6.64 \pm 0.30$ & $6.71 \pm 0.28$ & $5.20 \pm 0.63$ & $5.07 \pm 0.45$ \\
\hline Endoglin $(\mathrm{ng} / \mathrm{ml})$ female babies & $6.63 \pm 0.29^{+}$ & $6.49 \pm 0.24^{+}$ & $5.32 \pm 0.22^{+}$ & $4.87 \pm 0.77^{*}$ \\
\hline
\end{tabular}

$* \mathrm{p}>0.05$ as compared to male babies

\section{DISCUSSION}

Failure of physiological transformation of the spiral arteries is the central feature of pathophysiology of (PE). ${ }^{1}$ The resulting poor placentation and reduced placental perfusion (or ischemia-reperfusion injury to the placenta) in early pregnancy leads to the release of factors into the maternal circulation that cause systemic endothelial cell dysfunction, intravascular inflammation and multiple organ damage. These factors include cytokines, syncytiotrophoblast microparticles, apoptotic products, reactive oxygen species, activated leukocytes, 
angiotensin II type 1 receptor antibody, soluble vascular endothelial growth factor receptor (sVEGFR) and soluble endoglin (sEng). ${ }^{2-4}$

The soluble form of endoglin (s-Eng) is considered to have anti-angiogenic effects, and shedding has been proposed to account for circulating s-Eng. ${ }^{6}$ This antiangiogenic factor has been recently implicated in the pathophysiology of preeclampsia (PE). ${ }^{6,7}$

A number of studies have reported that circulating sEng levels in women with preeclampsia after the onset of clinical disease are increased compared with those in normal pregnant women. ${ }^{6-8}$

In the present study, maternal serum endoglin levels were decreased in group II as compared to group I (5.25 \pm 0.52 vs $6.64 \pm 0.30 \mathrm{ng} / \mathrm{ml}, \mathrm{p}<0.001$; Table 1$)$. Cord blood endoglin levels were also decreased in babies of preeclamptic mothers (group II) as compared to normotensive mother (group I) $[5.01 \pm 0.58$ vs. $6.60 \pm 0.28$ ng/ml, $\mathrm{p}<0.001$; Table 1).

Romero et al studied soluble endoglin (s-Eng), sVEGFR1 and PlGF in patients with uncomplicated pregnancies who delivered appropriate for gestational age (AGA) neonates; patients who delivered an SGA neonate but did not develop PE and patients who developed PE. All these patients had significantly higher concentrations of s-Eng than those with normal pregnancies. Patients who developed PE later in pregnancy showed higher plasma concentrations of s-Eng than those with normal pregnancies before the onset of preeclampsia. ${ }^{9}$ However, no reports are available in literature regarding serum endoglin levels in PE at term.

The maternal serum endoglin and cord blood levels were comparable in group I $(6.64 \pm 0.30 \mathrm{ng} / \mathrm{ml}$ vs $6.60 \pm 0.28$ $\mathrm{ng} / \mathrm{ml}, \mathrm{p}>0.05)$. Maternal serum endoglin levels were higher as compared to cord blood in group II, though, the difference was not statistically significant $(5.25 \pm 0.52$ vs. $5.01 \pm 0.58 \mathrm{ng} / \mathrm{ml}, \mathrm{p}>0.05)$. Positive correlation was observed between maternal serum endoglin levels with gestational age in both preeclamptics $(\mathrm{r}=0.099, \mathrm{p}>0.05)$ and normotensive pregnant women, but it was not statistically significant $(\mathrm{r}=0.165, \mathrm{p}>0.05)$. Negative correlation was observed between cord blood endoglin levels with gestational age in both preeclamptics $(r=-$ $0.318, p>0.05$ ) and normotensive pregnant women but not statistically significant in both the groups $(r=-0.167$, $\mathrm{p}>0.05)$.

There is considerable contemporary interest in the fact that low birth weight predicts those in later life predisposed to atherosclerotic cardiovascular diseases.10 In the present study, the mean birth weight was $2.29 \pm 0.18$ in group I and $2.34 \pm 0.19 \mathrm{~kg}$ in group II. There was no statistical significant difference between the two groups ( $\mathrm{p}>0.05)$. Pre-eclamptics with birth weight less than 2.5 $\mathrm{kg}$ had lower serum endoglin levels as compared to controls $(5.25+0.52 \mathrm{ng} / \mathrm{ml}$ vs. $6.64+0.30 \mathrm{ng} / \mathrm{ml}, \mathrm{p}<0.05)$ in maternal blood reflecting a perturbation in angiogenic state. Cord blood endoglin levels were lowered in group II $(4.99 \pm 0.66 \mathrm{ng} / \mathrm{ml}$ vs. $5.04 \pm 0.29 \mathrm{ng} / \mathrm{ml}, \mathrm{p}>0.05)$ as compared to those born with birth weight greater than 2.5 $\mathrm{kg}$ in group II. Babies born with birth weight less than 2.5 $\mathrm{kg}$ had lower maternal endoglin levels as compared to those with $>2.5 \mathrm{~kg}(5.22 \pm 0.60 \mathrm{ng} / \mathrm{ml}$ vs. $5.30 \pm 0.18 \mathrm{ng} / \mathrm{ml}$, $\mathrm{p}>0.05)$, cord blood endoglin levels were lowered in babies with birth weight less than $2.5 \mathrm{~kg}(4.99 \pm 0.66$ $\mathrm{ng} / \mathrm{ml}$ vs. $5.04 \pm 0.29 \mathrm{ng} / \mathrm{ml}, \mathrm{p}>0.05)$ as compared to those born with birth weight greater than $2.5 \mathrm{~kg}$ in group II. Low birth weight can affect the risk of suffering from cardiovascular diseases later in life. ${ }^{11}$ Reduced fetal growth carries a risk of hypertension and ischemic heart disease in later years. ${ }^{12,13}$

An inverse relationship between plasma sEng concentrations and gestational age at delivery, and neonatal birth weight has been reported in the literature and they suggested that abnormalities in the placental blood vessels were associated with the 'antiangiogenic state', defined as an increase in sEng and sVEGFR-1 concentrations, with a decrease in PIGF concentrations in the maternal circulation of patients with preeclampsia.,3,9,14,15 Endoglin and soluble endoglin expression have been reported to be significantly increased in placentas of IUGR singletons compared to controls and in the IUGR twin placentas relative to both the control co-twin and the normal twins. ${ }^{16}$ Laskowska et al reported increased endoglin levels in women with normotensive pregnancy complicated by IUGR and in preeclamptics with and without IUGR. These finding suggest that endoglin levels may responsible for the pathogenesis of PE and/or IUGR. ${ }^{17}$ Increase in soluble endoglin may, in turn, create an anti-angiogenic milieu in the circulation and lead to the maternal manifestations of preeclampsia. The effect of gestational age at delivery on the differences in level is not known and further studies are required in this aspect to explore whether primary pathology is uteroplacental response to fetal placental vasculature or uterine circulation constraints on placenta and foetus.

Szentpeteri et al reported significant overexpression of placental endoglin gene in pregnancy with IUGR as compared to normal pregnancy. Increased endoglin expression could be a result of feedback response to restore fetal placental circulation. Since increased placental endoglin may result in vascular dysfunction leading to chronic fetal hypoxia that can induce VEGF to stimulate angiogenesis. ${ }^{19}$ Redman and Sargent suggested that apart from hypoxia as one of the trigger for the release of antiangiogenic factors, inflammatory mechanisms may also contribute or even predominate under normoxic conditions. ${ }^{20}$

Babies with Apgar score $<7$ showed lower maternal and cord blood endoglin levels as compared to those with Apgar score $>7$ in group II $(5.08 \pm 0.76 \mathrm{ng} / \mathrm{ml}$ vs. 
$5.35 \pm 0.23 \mathrm{ng} / \mathrm{ml}, \mathrm{p}>0.05 ; 4.83 \pm 0.79 \mathrm{ng} / \mathrm{ml}$ vs. $5.12 \pm 0.37$ $\mathrm{ng} / \mathrm{ml}$ respectively $\mathrm{p}>0.05$ ), but statistically not significant in both the groups. These findings support the influence of maternal status on that of the descendants.

Endoglin levels positively correlated with both systolic and diastolic blood pressures $(r=0.197, \mathrm{p}>0.05 ; \mathrm{r}=0.076$, $\mathrm{p}>0.05$ respectively) of pre-eclamptic mothers, but, it was not statistically significant.

The present study explored role of endoglin as a potential marker and its association with clinically relevant pregnancy outcomes. The findings of the present study confirm a relationship between raised blood pressures in pregnant women and adverse outcomes, including relatively low birth weight of the new born babies. The correlations described above raise the need to further explore the maternal vasculature with a view to evolving novel, but safe therapies targeting these specific pathways so as to prevent the development of hypertensive disorders in pregnancy and hence preventing any adverse outcomes.

The findings of the present study add to the understanding of role of antiangiogenic factors in the pathophysiology of pre-eclampsia. An 'antiangiogenic state' (defined by maternal concentrations of sEng) occurring in pre-eclampsia is associated with poor perfusion in the fetomaternal circulation.

\section{Funding: No funding sources}

Conflict of interest: None declared

Ethical approval: The study was approved by the Institutional Ethics Committee

\section{REFERENCES}

1. Chaiworapongsa T, Romero R, Kusanovic JP, Mittal P, Kim SK, Gotsch F et al. Plasma soluble endoglin concentration in pre-eclampsia is associated with an increased impedance to flow in the maternal and fetal circulations. Ultrasound Obstet Gynecol. 2010;35:155-62.

2. Maynard SE, Min JY, Merchan J, Lim KH, Li J, Mondal $\mathrm{S}$ et al. Excess placental soluble fms-like tyrosine kinase 1 (sFlt1) may contribute to endothelial dysfunction hypertension, and proteinuria in preeclampsia. J Clin Invest. 2003;111:649-58.

3. Venkatesha S, Toporsian M, Lam C, Hanai J, Mammoto T, Kim YM et al. Soluble endoglin contributes to the atherogenesis of preeclampsia. Nature Med. 2006;12:642-9.

4. Redman CW, Sargent IL. Latest advances in understanding preeclampsia. Science. 2005;308(5728):1592-4.

5. Kapur NK, Morine KJ, Letarte M. Endoglin: a critical mediator of cardiovascular health. Vasc Health Risk Manag. 2013;9:195-206.

6. Alt A, Miguel-Romero L, Donderis J, Aristorena M, Blanco FJ, Round A et al. Structural and functional insights into endoglin ligand recognition and binding. PLoS One. 2012;7(2):e29948.

7. Castonguay R, Werner ED, Matthews RG, Presman E, Mulivor AW, Solban N et al. Soluble endoglin specifically binds bone morphogenetic proteins 9 and 10 via its orphan domain, inhibits blood vessel formation, and suppresses tumor growth. J Biol Chem. 2011;286:30034-46.

8. Cudmore MJ, Ahmad S, Sissaoui S, RammaW, Ma Bin, Fujisawa $\mathrm{T}$ et al. Loss of Akt activity increases circulating soluble endoglin release in preeclampsia: identification of inter-dependency between Akt-1 and heme oxygenase-1. Eur Heart J. 2012;33:1150-8.

9. Romero R, Nien JK, Espinoza J, Todem D, Fu W, Chung $\mathrm{H}$ et al. A longitudinal study of angiogenic (placental growth factor) and anti-angiogenic (soluble endoglin and soluble VEGF receptor-1) factors in normal pregnancy and patients destined to develop preeclampsia and deliver a small-forgestational-age neonate. J Matern Fetal Neonatal Med. 2008;21:9-23.

10. Barker DJ. Intrauterine programmes of coronary heart disease and stroke. Acta Paediatr. 1997;423:178-82.

11. Haladay A. Early risk factors for cardiovascular disease. BNF Nutr Bull. 1990;15:6-7.

12. Barker DJ, Osmond C, Golding J, Kuh D, Wadsworth ME. Growth in utero blood pressure in childhood and adult life and mortality from cardiovascular disease. BMJ. 1989;298:564-7.

13. Barker DJP, Hunter PD, Osmonde, Margetts B, Simmonds SJ. Weight in infancy and death from ischaemic heart disease. Lancet. 1989;9:577-80.

14. Levine RJ, Maynard SE, Qian C, Lim KH, England $\mathrm{LJ}, \mathrm{Yu} \mathrm{KF}$ et al. Circulating angiogenic factors and the risk of preeclampsia. $\mathrm{N}$ Engl $\mathrm{J}$ Med. 2004;350:672-83.

15. Chaiworapongsa T, Romero R, Espinoza J, Bujold E, Mee KY, Goncalves LF, Gomez R, Edwin S. Evidence supporting a role for blockade of the vascular endothelial growth factor system in the pathophysiology of preeclampsia. Young investigator award. Am J Obstet Gynecol. 2004;190:1541-7.

16. Gotsch F, Kim YM, Kim CJ, Edwin S, Holtra J, Tarca AL et al. A link between inflammation/infection and anti-angiogenic state in preeclampsia: inflammatory mediators mimic effect of hypoxia on trophoblast by increasing sFlt-1 and decreasing placental growth factor production. International Society for the Study of Hypertension in Pregnancy 2009 World Congress XVI, Washington, DC, USA. 2008;46.

17. Yinon Y, Nevo O, Xu J, Many A, Rolfo A, Todros $\mathrm{T}$ et al. Severe intrauterine growth restriction pregnancies have increased placental endoglin levels. Am J Pathol. 2008;172:77-85.

18. Laskowska M, Laskowska K, Oleszczuk J. Endoglin in pregnancy complicated by fetal intrauterine growth restriction in normotensive and pre-eclamptic 
pregnant women: a comparison between preeclamptic patients with appropriate-for-gestationalage weight infants and healthy pregnant women. J Matern Fetal Neonatal Med. 2012;25:806-11.

19. Szentpéteri I, Rab A, Kornya L, Kovács P, Brubel B, Joó JG. Placental gene expression patterns of endoglin (CD105) in intrauterine growth restriction. Mat Fe Neo Med. 2014;27:350-4.
20. Redman CW, Sargent IL. Latest advances in understanding preeclampsia. Science. 2005;308(5728):1592-4.

Cite this article as: Kharb S, Tiwari R, Nanda S.

Relationship between gestational age and endoglin levels in maternal and cord blood. Int J Reprod

Contracept Obstet Gynecol 2016;5:770-4. 